\title{
ANALISIS TENSES YANG DIGUNAKAN DALAM FILM KUNG FU PANDA 3: RELEVANSI TERHADAP KURIKULUM 2013 UNTUK PENGAJARAN TENSES PADA SISWA SMP/MTs
}

\author{
Agus Wilson \\ Program Studi Teknik Informatika, Universitas Indraprasta PGRI \\ Email: wilsonaw2580@gmail.com
}

\begin{abstract}
Abstrak
Penelitian ini bertujuan untuk mengetahui tenses yang digunakan dalam naskah film Kung Fu Panda 3 dan hubungannya dengan kurikulum 2013 dalam pembelajaran tenses pada siswa SMP/MTs. Kurikulum 2013 dijadikan sebagai pedoman baku untuk menentukan kesesuaian kalimat. Penelitian ini merupakan penelitian kualitatif deskriptif dengan memanfaatkan metode analisis isi untuk menganalisis data. Sumber data terdokumentasi dari naskah film dan kurikulum bahasa Inggris 2013 untuk SMP/MTs. Hasil kajian disajikan dalam bentuk kalimat yang dianalisis dan diklasifikasikan ke dalam enam jenis tenses. Keenam tenses tersebut sesuai dengan kurikulum 2013, yaitu Simple Present Tense, Simple Past Tense, Present Continuous Tense, Past Continuous Tense, Present Perfect Tense, dan Present Future Tense. Hasil penelitian menunjukkan tingginya frekuensi relevansi antara tenses yang terdapat dalam naskah film dan kurikulum 2013 dengan total 100\%. Hasil penelitian ini menunjukkan bahwa naskah film Kung Fu Panda 3 dapat digunakan sebagai bahan pendukung bagi pengajar bahasa Inggris untuk mengajarkan tenses kepada siswa SMP/MTs.
\end{abstract}

Kata kunci : Kurikulum 2013, Tenses, Film Kung Fu Panda 3

\begin{abstract}
This study aims to find out the tenses used in the film script Kung Fu Panda 3 and its relations between the Curriculum 2013 in tenses learning for junior high school students. The Curriculum 2013 is used as a standard guide to determine the suitability of sentences. This research is descriptive qualitative research using content analysis techniques to analyze the data. Data source Documented film scripts and English Curriculum 2013 for junior high school. The study results are presented in the form of sentences that are analyzed and classified into six types of tenses. The six tenses are in accordance with the Curriculum 2013, namely Simple Present Tense, Simple Past Tense, Present Continuous Tense, Past Continuous Tense, Present Perfect Tense, and Present Future Tense. The study results show a high frequency of relevance to tenses located in film scripts and the Curriculum 2013 , with a total of 100\%. The results of this study show that the script of the Kung Fu Panda 3 film can be used as a support material for English teachers to teach tenses to junior high school students.
\end{abstract}

Key Words : Curriculum 2013, Tenses, Kung Fu Panda 3 Film

\section{PENDAHULUAN}

Bagi masyarakat Indonesia, bahasa Inggris bukanlah tergolong ke dalam kategori as a second language (bahasa kedua), apalagi as a mother tongue (bahasa ibu). Padahal bahasa Inggris sangat penting untuk dikuasai agar bisa berkomunikasi, berpolitik, bermasyarakat, berbudaya dan juga untuk berinteraksi di taraf internasional [1]. Tidak seperti (salah satunya) di Malaysia, bahasa Inggris digunakan dan bahkan telah menjadi bahasa kedua setelah bahasa Melayu dalam komunikasi sehari-hari hingga dunia usaha dan pendidikan [2]. Di Indonesia, khususnya dalam dunia pendidikan, bahasa Inggris masih dianggap sebagai bahasa asing. Teaching English as a Foreign Language (TEFL) merupakan pola pembelajaran yang dapat memberikan tantangan lebih bagi guru bahasa Inggris sebagai Bahasa Asing dibandingkan dengan Teaching English as a Second Language (TESL), di mana bahasa Inggris berperan sebagai bahasa kedua. Dalam pengajaran ESL dan EFL, guru membutuhkan materi yang mampu memotivasi pelajar dan memberi mereka 
masukan yang dibutuhkan [3]. Dalam hal ini guru dituntut agar lebih aktif dan kreatif dalam memilih model dan metode pembelajaran yang akan digunakan, seyogyanya harus bisa disesuaikan dengan situasi masyarakat saat ini serta tingkat kemampuan siswa, sehingga tujuan dari pembelajaran itu sendiri tetap tercapai [4].

Para guru harus mampu memberikan contoh nyata yang dapat dilihat oleh siswa seperti gambar, pamflet, poster, permainan, atau film. Tidak hanya dapat dilihat saja, akan lebih menarik jika model atau metode pembelajaran dapat didengar, diucapkan, dan dirasakan, sehingga dapat melibatkan langsung para siswa. Film merupakan media pembelajaran yang menghibur serta mampu menarik minat belajar bahasa Inggris siswa. Melalui film siswa dapat mendengar pengucapan yang benar dan melihat adegan, cerita, dan peristiwa yang terjadi. Media film sebagai alat penghubung yang berupa film, media komunikasi seperti tv, radio, koran, tabloid, majalah yang memberikan informasi kepada khalayak dan bisa mempengaruhi pikiran mereka [5]. Beberapa peneliti telah melakukan studi tentang pola pengajaran bahasa Inggris menggunakan film. Film merupakan media ajar yang disukai oleh peserta didik [6]. Film mampu meningkatkan minat belajar peserta didik [7]. Film memiliki dampak positif pada proses akuisisi belajar bahasa Inggris peserta didik [8]. Film animasi efektif meningkatkan keterampilan siswa dalam menulis narasi [9].

Dengan demikian, berdasarkan pemaparan beberapa peneliti terdahulu dapat dikatakan bahwa film merupakan bentuk media yang diminati sebagai model pembelajaran yang dapat dimanfaatkan saat pengajaran EFL (English as a Foreign Language), siswa dapat melihat dan mendapatkan kesempatan untuk mengembangkan keterampilan mendengar (listening) dan berbicara (speaking) mereka dengan bahasa asli sebagai model mereka.

Berdasarkan kurikulum bahasa Inggris 2013 tujuan pembelajaran bahasa Inggris lebih menitikberatkan pada keterampilan berkomunikasi dan menulis dengan kalimat yang tepat berdasarkan konteks, baik dalam bentuk lisan maupun tertulis. Salah satu materi bahasa Inggris yang diajarkan kepada siswa SMP/MTs dan harus dikuasai oleh mereka adalah tenses [4]. Penguasaan kemampuan berbahasa Inggris tidak luput dari peran tenses yang digunakan sebagai penunjuk waktu kejadian berlangsung [10]. Dengan kata lain sebenarnya ketika kita belajar tenses, yang kita pelajari adalah mengenai "waktu dan kata kerja".

Menyajikan tenses dengan film diharapkan dapat mendukung tujuan kurikulum. Film Kung Fu Panda 3 dipilih sebagai media untuk mengajarkan tenses bahasa Inggris. Film bergenre animation, action, dan adventure ini dirilis pada tahun 2016, diproduksi oleh DreamWorks Animation [11]. Penulis memiliki 3 (tiga) faktor penilaian dalam pemilihan film ini. Pertama, adegan dan bahasa yang disajikan mudah dicerna. Kedua, nilai moral berupa inspirasi gaya hidup sehat dan jiwa patriotisme yang dimunculkan cukup baik untuk membangun karakter positif siswa. Ketiga, mengandung banyak filosofi kehidupan dari yang sederhana hingga yang kompleks.

Beberapa penelitian sebelumnya juga telah dilakukan untuk menemukan nilai-nilai positif yang terkandung dalam film tersebut. [12], [13], [14], [15] menemukan bahwa bahasa sederhana dari tiap tokoh, jiwa patriotisme sebagai nilai kepahlawanan, serta rasa kekeluargaan dan kejujuran sebagai nilai moral muncul dalam Film Kung Fu Panda 3. 
Hal inilah yang melatarbelakangi penulis untuk meneliti film tersebut, untuk melihat jenis tenses yang digunakan di dalam film Kung Fu Panda 3 dan relevansinya dengan Kurikulum Bahasa Inggris 2013 untuk pengajaran tenses bahasa Inggris bagi siswa sekolah menengah pertama merupakan tujuan dari penelitian ini.

\section{METODE}

Penulis menggunakan metode deskriptif dengan pendekatan kualitatif dengan menggali informasi lebih dalam terkait topik yang akan diteliti sehingga menghasilkan informasi untuk menentukan tujuan penelitian ini. Penelitian deskriptif memberikan uraian secara sistematis tentang fakta yang ada [16]. Pendekatan kualitatif menggunakan analisis data untuk memeriksa dan mencatat isyarat-isyarat kecil untuk memahami konteks dan membangun ilustrasi yang lebih besar untuk data [17]. Metode deskriptif kualitatif yaitu metode penelitian yang memiliki tujuan untuk menganalisis informasi yang menjadi subyek penelitian dengan mendeskripsikan secara terperinci tentang beragam fenomena yang muncul sehingga jelas ciri, karakter, dan sifat dari fenomena tersebut [18].

Kurikulum Bahasa Inggris SMP/MTs 2013 dan Naskah Film Kung Fu Panda 3 menjadi sumber data utama yang didokumentasikan. Proses pengumpulan data melalui membaca sumber data utama tersebut secara berulang-ulang, hingga penulis menemukan dan mengklasifikasikan kalimat dengan tenses berdasarkan kurikulum 2013, yaitu Simple Present Tense, Simple Past Tense, Present Continuous Tense, Simple Future Tense, Present Perfect Tense, dan Past Continuous Tense. Demi menjamin keakuratan data, penulis melakukan observasi saat proses pemilihan data dilakukan.
Penulis memakai metode analisis isi untuk menganalisis data dalam penelitian ini. Sebagai proses awal penulis meneliti kompatibilitas antara sumber data utama dengan tata bahasa Inggris (grammar). Selanjutnya kalimat-kalimat yang memiliki tenses di dalamnya dihitung dan dikelompokan ke dalam tiap-tiap jenis tenses dan diberi persentase. Setelah itu, penelitian ini menguji relevansi kalimat dengan topik pembelajaran tenses bahasa Inggris dalam Kurikulum SMP/MTs 2013.

\section{HASIL DAN PEMBAHASAN \\ Jenis Tenses yang Digunakan dalam Film Kung Fu Panda 3}

Setelah menganalisis data dalam naskah film Kung Fu Panda 3, ada 819 kalimat dengan tenses bersesuaian dengan 10 jenis gramatikal tenses bahasa Inggris (tabel 1). Persentase penggunaan tiap tenses dalam film Kung Fu Panda 3 sebagai berikut:

\section{Tabel 1. Jenis Tense yang Digunakan} Kung Fu Panda 3

\begin{tabular}{lcc}
\hline \multicolumn{1}{c}{ Jenis Tense } & $\begin{array}{c}\text { Jumlah } \\
\text { Kalimat }\end{array}$ & $\begin{array}{c}\text { Persentase } \\
(\%)\end{array}$ \\
\hline Simple Present & 493 & $60 \%$ \\
Simple Past & 164 & $20 \%$ \\
Simple Future & 68 & $8 \%$ \\
Past Future & 7 & $1 \%$ \\
Present Continuous & 45 & $5 \%$ \\
Past Continuous & 10 & $1 \%$ \\
Future Continuous & 1 & $0 \%$ \\
Present Perfect & 28 & $3 \%$ \\
Past Perfect & 1 & $0 \%$ \\
Present Perfect & 2 & $0 \%$ \\
Continuous & 819 & $98 \%$ \\
\hline \multicolumn{2}{c}{ Total Kalimat } &
\end{tabular}

Dari tabel di atas terlihat bahwa Simple Present Tense merupakan tense yang paling sering digunakan, dengan jumlah 493 kalimat (60\%). Lebih dari setengah tenses yang terdapat dalam film Kung $\mathrm{Fu}$ Panda 3 menggunakan simple present tense. Tabel di atas menunjukkan jumlah kalimat spesifik untuk setiap tense yang telah sesuai dengan grammatical rules. 


\section{Kesesuain Pengajaran Tenses di SMP/MTs Berdasarkan Kurikulum}

Berdasarkan Kurikulum 2013, kesesuaian kalimat dengan tenses dalam film dengan kurikulum bahasa Inggris 2013 SMP/MTs sejalan dengan kompetensi dasar pembelajaran tenses di SMP. Topik pengajaran tenses lebih khusus diajarkan untuk kelas VIII dan IX SMP/MTs. Seperti yang ditampilkan pada Tabel 2 dan Tabel 3.

Tabel 2. Penerapan Tenses dalam Kurikulum Bahasa Inggris SMP/MTs Tahun 2013 untuk Siswa Kelas VIII

\begin{tabular}{|c|c|c|}
\hline $\begin{array}{c}\text { Kompetensi } \\
\text { Dasar\# }\end{array}$ & Kompetensi Dasar & $\begin{array}{c}\text { Tenses } \\
\text { yang } \\
\text { Terlibat }\end{array}$ \\
\hline 3.7 & $\begin{array}{l}\text { Menerapkan struktur teks } \\
\text { dan unsur kebahasaan } \\
\text { untuk menjalankan fungsi } \\
\text { sosial dengan memberi dan } \\
\text { meminta informasi terkait } \\
\text { tindakan/peristiwa yang } \\
\text { terjadi / biasa terjadi dan } \\
\text { kebenaran umum, } \\
\text { berdasarkan konteks. }\end{array}$ & $\begin{array}{l}\text { Simple } \\
\text { Present }\end{array}$ \\
\hline 4.7 & $\begin{array}{l}\text { Menyusun teks lisan dan } \\
\text { tulis sangat pendek dan } \\
\text { sederhana memberi dan } \\
\text { meminta informasi terkait } \\
\text { keadaan / peristiwa yang } \\
\text { biasa terjadi dan } \\
\text { merupakan kebenaran } \\
\text { umum, sesuai teks. }\end{array}$ & $\begin{array}{l}\text { Simple } \\
\text { Present }\end{array}$ \\
\hline 3.8 & $\begin{array}{l}\text { Menerapkan struktur teks, } \\
\text { dan unsur kebahasaan } \\
\text { dalam fungsi sosial dengan } \\
\text { memberi dan meminta } \\
\text { informasi tentang keadaan } \\
\text { / peristiwa yang sedang } \\
\text { dilakukan / berlangsung } \\
\text { pada saat ini. }\end{array}$ & $\begin{array}{c}\text { Present } \\
\text { Continuous }\end{array}$ \\
\hline 4.8 & $\begin{array}{l}\text { Menyusun teks lisan dan } \\
\text { tulis sangat pendek dan } \\
\text { sederhana saat memberi } \\
\text { dan meminta informasi } \\
\text { terkait keadaan / tindakan } \\
\text { yang sedang dilakukan / } \\
\text { pada saat ini. }\end{array}$ & $\begin{array}{c}\text { Present } \\
\text { Continuous }\end{array}$ \\
\hline 3.11 & $\begin{array}{l}\text { Membandingkan struktur } \\
\text { teks, dan beberapa teks } \\
\text { personal recount lisan } \\
\text { maupun tertulis saat } \\
\text { menjalankan fungsi sosial }\end{array}$ & $\begin{array}{c}\text { Simple } \\
\text { Past }\end{array}$ \\
\hline
\end{tabular}

dengan memberi maupun meminta informasi terkait pengalaman pribadi di masa lampau.

Menangkap makna teks

recount lisan dan tertulis mentenai

Simple pribadi di masa lampau.

Menyusun teks recount lisan maupun tertulis

berpola sederhana, terkait Simple
pengalaman pribadi di Past

berpola sederhana, terkait Simple
pengalaman pribadi di Past masa lampau (personal recount)

Sumber: Kurikulum Bahasa Inggris 2013

Tabel 3. Penerapan Tenses dalam Kurikulum Bahasa Inggris SMP/MTs Tahun 2013 untuk Siswa Kelas IX

\begin{tabular}{|c|c|}
\hline $\begin{array}{c}\text { Kompetensi } \\
\text { Dasar\# }\end{array}$ & Kompetensi Dasar \\
\hline
\end{tabular}

Menerapkan struktur teks, dan unsur kebahasaan dengan melibatkan tindakan memberi dan meminta informasi terkait keadaan/tindakan/ yang sedang atau terjadi pada saat ini, waktu lampau, dan yang akan datang berdasarkan konteks.

Menyusun teks lisan maupun tulis sangat pendek dan sederhana dengan memberi dan

4.5 meminta informasi mengenai keadaan / kejadian yang sedang atau terjadi saat ini, waktu lalu,

Present

Continuous

; Past

Continuous

; Present

Future dan akan datang.

Menerapkan struktur teks, dan unsur kebahasaan baik lisan dan tulis ketika memberi maupun meminta informasi mengenai

3.6 keadaan/kejadian yang telah dilakukan/terjadi di masa lampau dihubungkan dengan saat ini, tanpa menyebut waktu terjadinya.

Menyusun teks lisan maupun tulis sangat pendek dan sederhana mengaitkan dengan tindakan memberi dan
Present Perfect

Present

Present

Continuous

; Past

Continuous

; Present

Future

Perfect 
meminta informasi

keadaan/kejadian yang

telah terjadi di masa lalu

dihubungkan dengan

keadaan sekarang, tanpa

menyebutkan kapan

terjadinya.

Membandingkan fungsi

sosial, beberapa teks naratif lisan dan tertulis

3.7 saat memberi dan meminta informasi terkait fairytales, ke dalam bentuk sederhana.

Menangkap arti berdasarkan konteks, dan unsur kebahasaan teks

4.7 naratif, lisan dan tertulis sangat pendek dan sederhana, mengenai fairy tales.

Membandingkan struktur teks serta unsur kebahasaan mengenai information report dengan memberi maupun meminta informasi terkait pokok bahasan lain di Kelas IX, secara sederhana.

Menangkap arti secara kontekstual yang berhubungan dengan fungsi sosial berdasarkan konteks, information report baik lisan dan tertulis secara sederhana, terkait topik yang ada dalam pokok bahasan lain di Kelas IX.

Menyusun teks information report lisan dan tulis, sangat pendek dan sederhana, mengenai topik dalam mata pelajaran lain di Kelas IX, berdasarkan konteks, dan unsur kebahasaan.

Sumber: Kurikulum Bahasa Inggris 2013

Berdasarkan kompetensi dasar kurikulum bahasa Inggris 2013 untuk SMP/MTs yang terdiri atas enam jenis tenses: Simple Present Tense, Simple Past Tense, Present Continuous Tense, Past Continuous Tense, Present Perfect Tense, dan Present Future Tense. Tujuan dari kompetensi tersebut

Simple

Past

Simple

Simple

Simple diharapkan dapat dikuasai oleh siswa. Persentase relevansi antara kalimat dan kurikulum ditampilkan dalam tabel berikut ini.

\section{Tabel 4. Jenis Tense yang Digunakan} Kung Fu Panda 3

Present

Present

Present

\begin{tabular}{lcc}
\hline \multicolumn{1}{c}{ Jenis Tense } & $\begin{array}{c}\text { Jumlah } \\
\text { Kalimat }\end{array}$ & $\begin{array}{c}\text { Persentase } \\
(\%)\end{array}$ \\
\hline Simple Present & 513 & $60 \%$ \\
Simple Past & 163 & $20 \%$ \\
Simple Future & 71 & $8 \%$ \\
Present Continuous & 44 & $6 \%$ \\
Past Continuous & 11 & $1 \%$ \\
Present Perfect & 27 & $3 \%$ \\
\hline \multicolumn{1}{c}{ Total Kalimat } & 808 & $100 \%$ \\
\hline
\end{tabular}

Tabel 4 di atas menunjukkan nilai absolut $100 \%$ tenses yang digunakan dalam film Kung $\mathrm{Fu}$ Panda 3 sesuai dengan kompetensi dasar kurikulum 2013 dalam pengajaran bahasa Inggris. Dari hasil tersebut, dapat disimpulkan bahwa kalimat-kalimat dengan tenses yang digunakan oleh film dapat digunakan sebagai alternatif lain dalam pembelajaran tenses bahasa Inggris kepada siswa SMP/MTs, terutama di kelas VIII dan IX. Tujuan dari dilakukannya penelitian ini ialah demi mengetahui jenis tenses yang digunakan dalam naskah film Kung $\mathrm{Fu}$ Panda 3 dan relevansi tenses dan Kurikulum Bahasa Inggris 2013 dalam pengajaran tenses pada siswa SMP/MTs. Seperti yang telah diuraikan di dalam hasil penelitian ini, terdapat 819 kalimat dengan tenses yang ditemukan dalam film dan diklasifikasikan ke dalam sepuluh jenis tenses. Dari semua kalimat tersebut, tidak semuanya sesuai dengan kurikulum. Kalimat yang sesuai dengan kurikulum sebanyak 808 kalimat dari total 819 kalimat. Artinya $100 \%$ kalimat dengan tenses dalam naskah film relevan dengan kurikulum. Tenses tersebut adalah Simple Present Tense 60\% (513 kalimat), Simple Past Tense 20\% (163 kalimat), Simple Future Tense 8\% (71 kalimat), Present Continuous Tense 6\% (44 kalimat), Past Continuous Tense 1\% (11 kalimat). ), dan 
Present Perfect Tense 3\% (27 kalimat). Data tersebut menunjukkan frekuensi relevansi yang tinggi di antara keduanya, terutama Simple Present Tense dengan persentase tertinggi, $60 \%$ (513 kalimat). Film animasi keluarga bergenre action comedy ini banyak menggunakan Simple Present Tense dalam tayangannya. Hal ini memperlihatkan bahwa target penontonnya adalah semua umur, terutama anak-anak. Penjelasan di atas menunjukkan bahwa film ini dapat digunakan sebagai bahan penunjang pembelajaran untuk mengajarkan tenses, khususnya Simple Present Tense.

Beberapa pola tenses menurut John Eastwood [19] beserta contoh dari masingmasing tenses yang digunakan dalam naskah film:

1. Simple Present Tense

$(+): \mathrm{S}+\mathrm{V}^{1}(\mathrm{~s} / \mathrm{es})+\ldots$

$(-): \mathrm{S}+\mathrm{Do} /$ Does + not $+\mathrm{V}^{1}+\ldots$

(?): Do/Does $+\mathrm{S}+\mathrm{Verb}^{1}+\ldots$ ?

\begin{tabular}{l}
\hline Kung Fu Panda 3 - Notepad $-\square$ \\
\hline File Edit Format View Help \\
\hline 649 \\
$00: 50: 58,934-->00: 51: 00,937$ \\
Do you forg1ve him? \\
$<$ \\
\hline
\end{tabular}

Gambar 1.

Contoh Simple Present Tense dalam Naskah Film

2. Simple Past Tense

$(+): \mathrm{S}+\mathrm{V}^{2}+\ldots$

$(-): \mathrm{S}+\mathrm{Did}+\mathrm{not}+\mathrm{V}^{1}+\ldots$

(?): $\mathrm{Did}+\mathrm{S}+\mathrm{Verb}^{1}+\ldots$ ?

\begin{tabular}{|l|}
\hline \multicolumn{3}{|l}{ Kung Fu Panda 3-Notepad $-\square$} & $\times$ \\
\hline File Edit Format View Help \\
\hline 437 \\
$00: 33: 32,796-->00: 33: 34,290$ \\
- Li? \\
- He found his son! \\
\begin{tabular}{l}
\hline \\
\hline
\end{tabular} \\
\hline
\end{tabular}

Gambar 2.

Contoh Simple Past Tense dalam Naskah Film
3. Simple Future

$(+): \mathrm{S}+$ will $+\mathrm{V}^{1}+\ldots$

$(-): \mathrm{S}+$ will $+\mathrm{Not}+\mathrm{V}^{1}+\ldots$

(?): Will $+\mathrm{S}+\mathrm{Verb}^{1}+\ldots$ ?

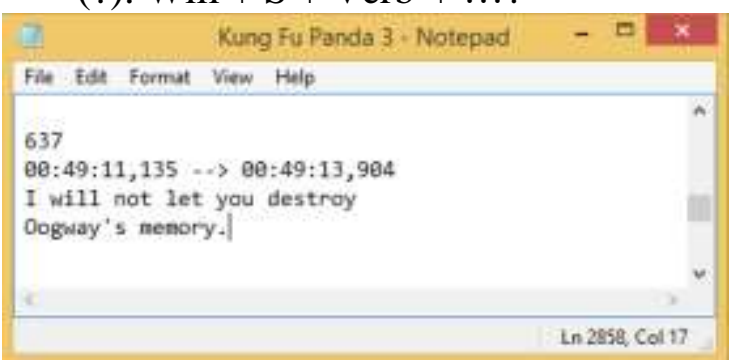

Gambar 3.

Contoh Simple Future Tense dalam Naskah Film

4. Present Continuous Tense

$(+): \mathrm{S}+$ to be (is/am/are) $+\mathrm{V}^{\text {ing }}+\ldots$

(-) $: \mathrm{S}+$ to be (is/am/are) + not $+\mathrm{V}^{\text {ing }}$ $+\ldots$

(?): to be (is/am/are) $+\mathrm{S}+\mathrm{V}^{\text {ing }}+\ldots$ ? Kung Fu Panda 3 - Notepad - $-x$

File Edit Format View Help
959
$01: 19: 43,797 \quad-\rightarrow 01: 19: 47,126$
I'n not going anywhere. I live here.
$\operatorname{Ln} 4274, \mathrm{Col} 37$

Gambar 4.

Contoh Present Continuous Tense dalam Naskah Film

5. Past Continuous Tense

$(+): \mathrm{S}+$ to be (was/were) $+\mathrm{V}^{\text {ing }}+\ldots$

$(-): \mathrm{S}+$ to be (was/were $)+$ not $+\mathrm{V}^{\text {ing }}$ + .

(?): to be (was/were $)+S+V^{\text {ing }}+\ldots$ ? Kung Fu Pandin 3 - Notepad File fdet Formet View Help

484

$00: 36: 31,625 \rightarrow \infty 0: 36: 34,821$

I knew I wasn"t eating up to my potentialt

Ln 2194 Cod 1

Gambar 5.

Contoh Past Continuous Tense dalam Naskah Film 
6. $\quad$ Present Perfect Tense

(+): $\mathrm{S}+$ have/has $+\mathrm{V}^{3}+\ldots$

(-) : $\mathrm{S}+$ have/has + not $+\mathrm{V}^{3}+\ldots$

(?): have/has $+\mathrm{S}+\mathrm{Verb}^{3}+\ldots$ ?

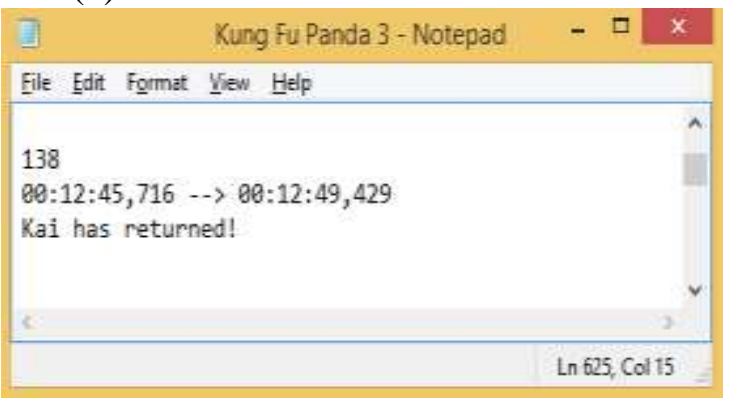

Gambar 6.

Contoh Present Perfect Tense dalam Naskah Film

Berdasarkan uraian di atas, dapat dikatakan bahwa sebagian besar naskah film Kung $\mathrm{Fu}$ Panda 3 terdiri dari kalimat-kalimat yang memenuhi atau sesuai dengan syarat tenses. Guru bahasa Inggris dapat menggunakan film ini sebagai bahan pembelajaran untuk mengajarkan tenses kepada siswa SMP/MTs. Film ini berdurasi sembilan puluh lima menit untuk diputar. Guru dapat meminta siswa agar menonton film lengkap di rumah terlebih dahulu sebelum menghadiri kelas.

Mereka dapat menunjukkan beberapa contoh tenses dari naskahnya seperti yang disajikan pada beberapa gambar di atas. Kalimat-kalimat ini diambil dari subtitle bahasa Inggris dari film tersebut. Kemudian, guru dapat memutar film dengan subtitle bahasa Inggris. Selanjutnya, memainkan beberapa bagian dari film, lalu meminta kepada seluruh siswa agar menulis jenis tenses untuk dibahas ketika memulai kelas. Juga, mereka dapat memainkan beberapa bagian secara acak dan bertanya kepada siswa apa jenis tenses itu. Selain itu, mereka menjelaskan kapan tenses harus digunakan dan aksi tenses yang dilakukan oleh karakter berdasarkan adegan bagian itu. Setelah siswa memahami, guru dapat memberikan beberapa latihan kepada mereka. Misalnya, guru dapat membagi siswa menjadi beberapa kelompok. Mereka diminta untuk mencari beberapa kalimat dengan tenses tertentu dari film dan menuliskannya di selembar kertas. Hal ini dapat membawa suasana baru bagi siswa karena mereka belajar tenses sambil menikmati menonton film. Dari situ siswa juga akan memahami penggunaan tenses berdasarkan situasi tertentu, dan mereka akan melihat dan memahami dengan jelas contoh tenses yang benar.

\section{SIMPULAN}

Berdasarkan hasil dan pembahasan, dapat disimpulkan bahwa naskah film Kung Fu Panda 3 memiliki relevansi yang signifikan dengan kurikulum bahasa Inggris 2013 SMP/MTs. Enam tenses yang ditemukan dalam naskah film sesuai dengan kompetensi dasar dalam kurikulum bahasa Inggris untuk mengajar SMP/MTs. Tenses tersebut adalah Simple Present Tense, Simple Past Tense, Present Future Tense, Present Continuous Tense, Past Continuous Tense dan Present Perfect Tense. Dalam film ini Simple Present Tense memiliki frekuensi yang paling banyak digunakan di antara tenses lainnya. Perihal ini selaras dengan target penonton film ini, yaitu anak-anak. Hal ini membuktikan bahwa film memiliki relevansi yang signifikan dengan kurikulum dan dapat digunakan sebagai bahan pembelajaran untuk mengajarkan tenses kepada siswa kelas VIII dan IX SMP/MTs, khususnya Simple Present Tense. Pengajaran tenses dengan menggunakan film ini dapat membawa suasana yang berbeda ke dalam kelas. Para siswa dapat mempelajari tenses darinya sambil menikmati menonton film.

\section{DAFTAR PUSTAKA}

[1] M. Behroozi and A. Amoozegar, "Challenges to English Language Teachers of Secondary Schools in 
Iran," Procedia - Soc. Behav. Sci., vol. 136, pp. 203-207, Jul. 2014.

[2] Wikipedia, "Bahasa Inggris Malaysia." [Online]. Available: https://id.vvikipedla.com/wiki/Malay sian_English. [Accessed: 10-May2021].

[3] V. Ruusunen, "Using Movies in EFL Teaching: The Point of View of Teachers," no. December, 2011.

[4] Kemdikbud, "Model Silabus Mata Pelajaran Sekolah Menengah Pertama/Madrasah Tsanawiyah (SMP/MTs),"

Http://Kemdikbud.Go.Id/, no. 21, pp. 1-55, 2017.

[5] Teguh Trianton, "Film sebagai Media Belajar." Yogyakarta: Graha Ilmu, 2013.

[6] W. Hanafiah, "Peningkatan Keterampilan Berbicara Bahasa Inggris Melalui Media Film," Epigram, vol. 16, no. 2, pp. 149-158, 2019.

[7] R. H. Kabooha, "Using Movies in EFL Classrooms: A Study Conducted at the English Language Institute (ELI), King Abdul-Aziz University.," English Lang. Teach., vol. 9, no. 3, pp. 248-267, 2016.

[8] P. R. Nath, M. Mohamad, and H. Yamat, "The Effects of Movies on the Affective Filter and English Acquisition of Low-Achieving English learners," Creat. Educ., vol. 8, no. 8, p. 1357, 2017.

[9] D. S. Mongar and N. Chalermnirundorn, "The Use of Animated Movies to Enhance Narrative Writing Skills of Grade Six Bhutanese ESL Students," Acad. J. Phranakhon Rajabhat Univ., vol. 11, no. 1, pp. 245-262, 2020.

[10] F. Iswari and P. Kurniasih, "Model Pembelajaran Kooperatif Jigsaw untuk Meningkatkan Hasil Belajar (Tenses) Mahasiswa DKV Unindra," SAP (Susunan Artik. Pendidikan), vol. 4, no. 3, 2020.

[11] IMDb, "Kung Fu Panda 3 (2016) IMDb," 2016. [Online]. Available: https://www.imdb.com/title/tt226796 8/. [Accessed: 15-May-2021].

[12] Y. Novi, "Moral Values in Kung Fu Panda 3 Movie." STKIP PGRI Sumatera Barat, 2017.

[13] A. M. Nasution, "Analisis Nilai Moral dan Nilai Budaya Cina dalam Film Animasi Kungfu Panda 3 Karya Jonathan Aibel dan Glenn Berger," 2019.

[14] A. K. Bhagaskoro, "The Representation Hero Of Po As Main Character In Kung $\mathrm{Fu} 3$ Panda Movies (2016)." UNIVERSITAS AIRLANGGA, 2020.

[15] S. Susanto, "AN ANALYSIS ON INTRINSIC ELEMENTS OF KUNGFU PANDA 3 MOVIE," Journey (Journal English Lang. Pedagog., vol. 2, no. 2, pp. 156-164, 2019.

[16] M. P. Prof. Dr. H. Wina Sanjaya, Penelitian Pendidikan: Jenis, Metode, dan Prosedur, Pertama. Jakarta, Indonesia: Kencana, 2015.

[17] S. J. Tracy, "Qualitative Research Methods: Collecting Evidence, Crafting Analysis, Communicating Impact." 2020.

[18] W. Sanjaya, "Penelitian Pendidikan Jenis, Metode dan Prosedur," Jakarta: Kencana, 2013.

[19] J. Eastwood, Oxford Practice Grammar.pdf, Second edi. New York: Oxford University Press, 1999. 